This item is the archived peer-reviewed author-version of:

\title{
Lookalike professional English
}

\section{Reference:}

Van Hout Tom, Van Praet Ellen.- Lookalike professional English

IEEE transactions on professional communication / Institute of Electrical and Electronics Engineers [New York, N.Y.] - ISSN 0361-1434 - 59:4(2016), p. 398-406

Full text (Publishers DOI): http://dx.doi.org/doi:10.1109/TPC.2016.2608198 
1 Teaching Case

\title{
Lookalike Professional English
}

\section{-Tom Van Hout and Ellen Van Praet}

\begin{abstract}
Background: Our teaching case reports on a fieldwork assignment designed to have master of arts students experience first-hand how entrepreneurs write for the globalized marketplace by examining public displays of language, such as billboards, shop windows, and posters. Research questions: How do entrepreneurs use English to "style" themselves? What is the status of English in public displays? Which relationship with customers is cultivated by using English (among other languages)? How does English, or lookalike versions thereof, create a more innovative business? Situating the case: We use linguistic landscaping as a pedagogical resource, drawing on similar cases in a local English as a foreign language (EFL) community in Oaxaca, Mexico; EFL programs in Chiba-shi, Japan; francophone and immersion French programs in Montreal, QC, Canada and Vancouver, BC, Canada; and a study of the entrepreneurial landscape in Observatory's business corridor of Lower Main Road in Cape Town, South Africa. How this case was studied: We interviewed 36 students about their learning process in one-to-one post hoc interviews. Recurrent themes were increased self-monitoring, improved professional communication literacy, and expanded real-world understanding. About the case: The teaching case follows a three-pronged approach. First, we have students decide on a survey area, determine their empirical focus, establish analytical units, decide how to collect data, collect (sociodemographic) information about their survey area, and determine the degree of researcher engagement. Next, students conduct fieldwork, documenting the linguistic landscape in small teams of three to four students. In the third phase, students have returned from the field and discuss their initial findings, ideas, and observations during a data session with the instructors. Students decide whether they still stand by the decisions they made before they entered the field and are then asked to qualify how language is used in public space. Results: The main takeaway of the assignment is that students were more aware of the degree of linguistic innovation, rhetorical creativity, and ethnocultural stereotyping of entrepreneurial communication in their cities. Conclusion: As a pedagogical tool, LL offers possibilities for exploring entrepreneurial communication in all of its breadth and variety, providing access to perhaps the most visible and creative materialities of entrepreneurs and service providers: shop windows and signs.
\end{abstract}

Index Terms-Entrepreneurship communication, linguistic landscape, lookalike English, professional communication.

Managing a business inevitably involves the rhetorical activity of creating value through writing [1], both online [2] and offline [3]. This teaching cases addresses the creation of economic value from the perspective of writing for the globalized marketplace. We send students on a semiotic safari in urban environments, where they encounter professional communication in multilingual couleur locale. We have them document the bits of English used by professional communicators on billboards, in shop windows, posters, graffiti, and other inscriptions. The rationale is that such displays of entrepreneurial communication offer a convenient

Manuscript received February 15, 2016; revised May 30, 2016; accepted July 5, 2016. Date of publication; date of current version.

T. Van Hout is with the Institute for Professional and Academic Communication at the University of Antwerp, Belgium, and the Department of Journalism and New Media, Leiden University the Netherlands (email: tom.vanhout@uantwerp.be).

E. Van Praet is with the Research Centre for Multilingual Practices and Language Learning in Society, Ghent University, Ghent, Belgium (email: Ellen.VanPraet@UGent.be). Color versions of one or more of the figures in this pap 2 . available online at http://ieeexplore.ieee.org. and socioculturally rich space for studying rhetorical action in situ [4].

\section{Overview of the Case}

nnovation and entrepreneurship are studied in many disciplines, including economics, sociology, psychology, linguistics, and anthropology. In the traditional Schumpeterian view, the innovation-management process is considered linear and continuous. In this teaching case, however, we adopt an approach to entrepreneurship that complements Schumpeterian innovation dynamics [5] with Appadurian scalar dynamics [6], and recognize that change in a globalized market is, by definition, chaotic, nonlinear, and unpredictable.

In his work on the cultural dimensions of globalization, anthropologist Arjun Appadurai famously argued that the global economy needs to be "understood as a complex, overlapping, disjunctive order" [6], composed of cultural flows between people, media, technologies, capital, and ideologies. Disturbing the even flow of production and creating new ways of doing, the Schumpeterian 
entrepreneur will instigate innovative language practices and, hence, unforeseen, artful, or otherwise "new combinations" of entrepreneurial communication. In other words, disjuncture also triggers rhetorical innovation.

Following this rationale, our teaching case addresses the following research questions:

RQ1. What are the effects of globalization on entrepreneurial communication?

RQ2. How do entrepreneurs use English to "style" themselves?

RQ3. Which relationship with customers is cultivated by using English (among other languages)?

RQ4. How does English, or lookalike versions thereof, create more innovative business signage?

In what follows, we report on how we coached and monitored students as they collected data in the field to answer these research questions. We explain the underlying rationale for developing the assignment and discuss implications for teachers and students of professional communication.

In line with other researchers of professional communication in Europe [7], [8], we draw on linguistics to understand how rhetorical action is accomplished. Specifically, we focus on public signage as a technological space for rhetorical action [9]. Rather than the outcome of a formal research project, this teaching case results from (1) our experience as instructors of professional communication, and (2) our backgrounds in sociolinguistics and linguistic ethnography. An umbrella term for ethnographic approaches to language and communication. Linguistic ethnography holds that "the contexts of communication should be investigated rather than assumed [and that] analysis of the internal organisation of verbal (and other kinds of semiotic) data is essential to understanding its significance and position in the world" [10].

In what follows, Situating the Case outlines the key studies and theories that guided the design of the assignment. How the Case was Studied explains why we relied on experiential learning as a pedagogical approach and why the assignment took on a clearer focus on entrepreneurial communication over time. About the Teaching Case describes how students were briefed, how they performed during data sessions with the instructors, and how they analyzed their data.
Conclusions, Limitations, and Suggestions for

Future Research spells out implications for teaching practice, the limitations of this case, and avenues for future research.

\section{Situating the Case}

This section identifies the literature that informed the teaching case. We start with the three source texts that inspired and provided the main scaffold for the case in How Literature Was Selected, followed by a discussion of similar cases.

How Literature Was Selected Our teaching case draws on recent debates in two fields: sociolinguistics and foreign language pedagogy. First and foremost, we were triggered by the concept of lookalike language [11]. Proliferating in urban spaces around the world, the bits of English used by professional communicators on billboards, in shop windows, posters, graffiti, and other inscriptions often appear "in forms and formats that challenge our understanding of language" [11]. They come with accents, typos, dialects, unintended meanings. They "sufficiently look like English, even if the English they display makes no sense at all linguistically. Their function is not to express coherent linguistic meanings through the system of English. It is, rather, to show and display an awareness of the potential social capital contained in forms and shapes connected to English" [11].

Rather than simply dismiss lookalike language as bad or non-native English, the concept compelled us to study occurrences of lookalike English as indicators of social change. (See also [12].) If students are to become successful in the modern globalized corporate world, they have to come to terms with the diversity, and "the unpredictability, which comes along with highly mobile, technological and multicultural citizens" [4]. Since no classroom experience can provide such knowledge first-hand, we turned to the sights and sounds of the city.

We used a linguistic landscape (LL) approach, a young and vibrant area of sociolinguistics that studies how written language constructs public places. LL research examines billboards, road signs, shop windows, graffiti, and other inscriptions in urban environments. Our second source of inspiration was an LL research assignment, developed by sociolinguist Jannis Androutsopoulos 
(1) Selection of a site

(2) Photographic documentation

(3) Selection of and contact with participants

(4) Conducting individual "walking tour" interviews on the selected site

(5) Transcription and analysis of interviews and field notes

\section{(6) Reflection}

Skipping Androutsopoulos' stages 3, 4, and 5, we structured our assignment around three phases. First, we let students decide on a survey area, determine their empirical focus, establish analytical units, decide how to collect data, collect (sociodemographic) information about their survey area, and determine the degree of researcher engagement. In the second phase, they conduct fieldwork, taking pictures, and documenting the linguistic landscape in small teams. In the third, reflective phase, students have returned from the field and discuss their initial findings, ideas, and observations during a data session with the instructor. Students decide whether they still stand by the decisions that they had made before they entered the field and are asked to qualify how language is used in public space. In this phase, students interpret the social actions accomplished by the signs and present their findings to their peers in a student research conference.

A third source of inspiration was found in Malinowski's [14] creative adoption of Henri Lefebvre's triple notion of conceived, perceived, and lived spaces for language learning. Applying the triadic model to second language pedagogy, Malinowski argues for a study of at least two dimensions in the LL. In terms of language learning, then, this approach means that students do not just visit areas with signs in the target language (English); or take pictures and sample lookalike language (perceived spaces); or conduct interviews with local entrepreneurs to probe for experiences, memories, and feelings (lived spaces). Ideally, students do all of these, alongside textual analysis of language policy documents, newspaper articles, and other media representations (conceived spaces).

Similar Cases In designing the teaching case, we were guided by a recent interest in using the LL as a pedagogical resource in second and foreign language learning in Mexico [15], Japan [16], and Canada [17]. Along the way, we discovered that using the LL as a site for business English learning seemed i $\rightarrow$ rgely unexplored territory. We were also inspred by Peck and Banda, who point an ethnographic lens at the entrepreneurial landscape in Observatory's business corridor of Lower Main Road in Cape Town, South Africa [4]. Their paper explores the development of an "African Corner" within Lower Main Road, and documents sociocultural change in ways that a population census could never uncover. In particular, their analysis shows how some Asian and African entrepreneurs openly celebrate Africanness and use it as an innovative marketing strategy, while others shy away from the overt use of signage, art, and texts that might foreground their Africanness.

\section{How This Case Was Studied}

In what follows we explain why we opted for autonomous, experiential learning as a pedagogical approach and why the assignment took on a clearer focus on entrepreneurial communication.

Advocating experiential learning in education is by no means new. Back in the early $19^{\text {th }}$ century, John Dewey argued for incorporating as much of current society into the educational process as possible to facilitate learning, which would then enhance society as a whole [18]. More recent studies show that experiential learning in business and accounting programs has become increasingly important. It has now become a taken-for-granted assumption among business and management educators and CEOs that universities must provide experiential learning programs, such as internships, real-life marketing cases, crisis communication, advertising, and the like. Business education-like the firms and students they serve-is in a continuous process of evolving to meet a shifting global and local environment. Fast-changing corporate settings, along with students' ever-increasing access to mobile technology and mediated content, force business programs to rethink how student learning can be facilitated to make class time and activities as relevant and valuable as possible.

Following this rationale, Author 1 piloted the assignment in 2014 at the University of Antwerp, where he teaches professional communication in English to about 70 students in the Master of Multilingual Professional Communication program. One year later, a slightly altered version of the assignment was launched by Author 2 at Ghent University for about 60 students of the Master of Multilingual Communication program. Both master's programs train students in multilingual communication skills for business, government, and nonprofit organizations. The master's program

\section{5}

\section{(24)}

\section{.}

\section{6} . . .

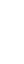
. . 
is typically_but not exclusively-populated by students with a background in (applied) linguistics. The courses in which the assignments were taught are required for all students registering for the two programs. Sessions with students were held on a once-a-week basis. A typical semester in Belgium starts at the end of September and lasts 12 weeks. At the University of Antwerp, six weeks were reserved for the assignment. At Ghent University, time for completing the assignment was limited to three weeks.

Since experiential learning is a complex construct and, therefore, difficult to measure, we tested our approach by interviewing 36 students about what they had learned in the course. In these one-to-one exit interviews, recurrent themes were increased self-monitoring, improved professional communication literacy, and expanded real-world understanding, but also a failure to see a link with professional communication in a foreign language. In fact, at the beginning, in Year 1, the assignment did not focus on entrepreneurial communication per se. Its scope was more general, focusing on aspects of language use in a globalized city. To better serve student needs, we adjusted the pilot version of the assignment in Year 2, addressing what students had identified as its strengths (lived experience) and shortcomings (lack of focus). This revised version of the assignment is the basis for the teaching case presented in this paper.

\section{About the Teaching Case}

This section describes the trigger for developing the case, the design of the assignment, the changes we made to each version of the assignment, and the results of our efforts, grounded in reflections and feedback from students.

Problem The LL assignment addresses three broad but related issues we encountered as instructors of professional communication in a foreign language.

(1) Managing student expectations: Students entered the course with the expectation that they would learn about professional communication from the perspective of native speakers in monolingually English corporate environments. But real-world communication-what with its creative language practices, and oddly peculiar local meanings - tends to have a disruptive effect on such ideals. In fact, we wanted students to engage with English as sociolinguists would: as an instrument of mobility, dislodged from resident, stable communities of speakers and freely moving across the globe in unpredictable flows [19].

(2) Engaging with multilingual resources: A learner's trajectory in English as a second or foreign language is commonly described in terms of acquiring monolingual fluency in the target language. For instance, the Common European Framework of Reference for Languages plots language proficiency on a scale from "basic user" over "independent user" to "proficient user." Such scales not only skate over the range of language resources that people use to make meaning (speech styles, jargon, genres, register) but also neglect the smatterings of other languages that speakers rely on to get meaning across. Observing and documenting LLs draws students' attention to the "multilayered, and often bitterly contentious processes by which sign-mediated, social meanings are produced in place" [14].

(3) Banking on lived experience: Whereas in more traditional ways of teaching professional communication skills, first exposure occurs via lectures, role plays, or simulations in class, we wanted students to examine first-hand contexts of entrepreneurial communication. Observing business communication in urban environments and interpreting it in the company of peers and instructors afterwards makes professional communication training in a foreign language not only more authentic, meaningful, and motivating but also produces richer in-class discussions of the social meanings of entrepreneurship communication, ultimately leading to a level of metacognition and reflection associated with deep learning.

Students were given three to six weeks to read up on LL research, conduct fieldwork, interpret their data, and present their findings in class. In addition to this time constraint, academic heterogeneity was a complicating factor. Both master's programs bring together students with backgrounds in (primarily) applied linguistics, communication, and applied economics. While we see this diversity as a strength rather than a weakness, it does require an effort to find common ground to describe and interpret the social meanings of entrepreneurial communication. Inevitably, some students will be familiar with the technical vocabularies of linguistics, while others will need to make an extra effort. To cope with the heterogeneity, and address students' diverse competency levels in sociolinguistics, we made sure 


\begin{tabular}{|c|c|}
\hline empirical focus & $\begin{array}{l}\text { linguistic innovation, semiotic creativity, ethnocultural } \\
\text { stereotyping, usage and status of English, unexpected } \\
\text { language combinations, lookalike language use, target } \\
\text { audience, social status }\end{array}$ \\
\hline analytical unit & $\begin{array}{l}\text { individual sign, shop window, specific chunk of space, which } \\
\text { material aspects, moving or static signs, mobile signs }\end{array}$ \\
\hline data collection & camera, smartphone, time of day, storage \\
\hline research area & $\begin{array}{l}\text { demographic or census data, location (Google Maps), } \\
\text { historical development, urban development plans and the like }\end{array}$ \\
\hline $\begin{array}{l}\text { degree of researcher } \\
\text { engagement }\end{array}$ & $\begin{array}{l}\text { snapshot observation and documentation (no engagement } \\
\text { with "the locals") or interacting with research sites and } \\
\text { participants; decisions about when, how and who to interview }\end{array}$ \\
\hline
\end{tabular}

Fig. 1. Pre-fieldwork decisions.

that they were equipped with reading materials and background knowledge of the methodology used. In Antwerp, students were instructed to read and discuss an academic article about LL research during class. In Ghent, a guest lecture on LL provided a point of departure, along with a classroom discussion on an LL research paper they were instructed to read.

Solution The purpose of the linguistic landscape assignment was to have master's students examine first-hand how entrepreneurs, such as business owners and service providers, make use of commercial space in urban environments by studying public displays of language in marketplace examples, such as billboards, shop windows, and posters. We circulated sign-up sheets with selected survey areas in Antwerp and Ghent. Students signed up in teams of 3 to 4 . To narrow their empirical focus, they answered the following questions:

(1) How are you going to organise your research team? Who is responsible for what?

(2) What data are you going to collect and why? Photos? Audio? Video? Field notes?

(3) What is the unit of analysis?

(4) What are the potential pitfalls of

(a) Carrying out fieldwork?

(b) Analysing the resulting data?
(5) How will you categorise your data?

(6) When choosing the data for presentation, what do you need to take into account?

(7) What additional information do you have/do you need about your street/square? Where can you find it?

In designing these questions, we relied on Androutsopoulos' listing of pre-fieldwork decisions [13]. (See Fig. 1.)

After thinking about and talking through the prefieldwork questions, students spread out all over the city to map the linguistic repertoire (which language[s]? what linguistic "bits"?) and language ranking (a top 10 of languages encountered) for their designated square or street. They collected photographs (see the example in Fig. 2), and live tweeted the research process using the designated course hashtags \#LLMPC15 and \#A4MC1516. While they were out in the field, we relied on the Twitter livestream to interact with them.

Process for Developing the Solution Having returned from the field with a bag full of observations, notes, and photographs, students were given feedback on how to analyze their data and make sense of their-at first glance-banal impressions. They were given the opportunity to discuss their preliminary findings during a data 


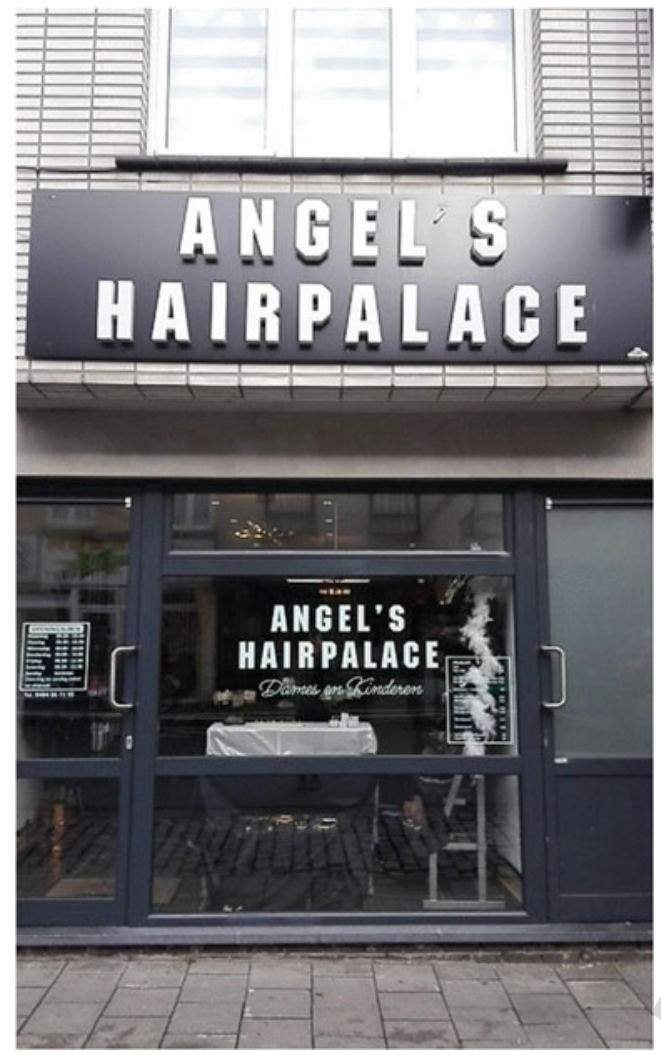

Fig. 2. Lookalike English: Angel's Hairpalace.

session. These sessions were run as peer-reviewed research consultations: two teams per 25-minute slot, 12 minutes per team. The goal of a data session was to try out "arguments on equally observant others ... and construct more insightful and persuasive analyses" [20].

During the sessions, we gave students advice on how to turn their dataset into an organized dataset from which they could draw significant trends or representative qualities. More specifically, we challenged students to look for clues about how entrepreneurial language is used and offered reading tips. In other words, we challenged them to determine relevant context (a crucial skill for budding professional communicators). Here is an excerpt from the data session briefing:

You will have observed a variety of business Englishes: carefully designed, expensive signs in perfect English as well as odd, elastic varieties of English so to speak. Some will have an "accent" ("love prices" instead of "lovely prices"). Now, you can dismiss those varieties as ungrammatical or substandard out of hand, but it gets far more interesting if you dig deeper.
Digging deeper means trying to determine which aspects of context are made relevant. The given context is what the sign communicates directly ("denotes"). Literal meanings. Product $x$ or $y$ is on sale. Categorize those meanings into functions. What is this sign doing here? Informing, persuading, promoting, you name it.

Signs (or "semiotic resources"-the tools we have at our disposal to make meaning) can also suggest or point to more subtle, indirect meanings. Signs often presuppose ("index") relevant context. For instance, English or French words in store names to signal prestige.

If you try to interpret how and why English is used, you'll find that public space is regimented (or governed by expectations of normative conduct): in order to attract rich clients, high end clothing shops will style themselves in particular ways. You will not for instance, expect to find hand-written signs in a Chanel store. You will however find such signs in a night shop.

There are no hard and fast rules for determining relevant context. What you can do is go over your data thoroughly and repeatedly and formulate ideas and interpretations of how you think English is being used in the marketplace.

One takeaway from the data sessions was that students found the fieldwork exciting but hard. Many students struggled to make sense of the unexpected linguistic practices they had observed, while others felt that their fieldwork was a failure because they found little or no diversity in the more commercial areas of town. Students also inquired about our expectations for the final deliverable. We replied by repeating what was on the assignment sheet: "Present an empirically and theoretically grounded interpretation of your fieldwork. Justify your data collection, reduction, and analysis, and interpret your findings. Show pictures. Reflect on what you have learned about the use of English in the marketplace but avoid linear, descriptive accounts of your research ("Here we see this and there that"-cue Ralph Wiggum: "Boring!"). We like a good story as much as you do."

Results Conducting research is an exercise in transparency, so we requested that students share their presentations and disclose their raw data (pictures) using a file-sharing service. The student presentations were a mixed bag of theoretically informed and empirically grounded accounts on the one hand, and overly descriptive and arid summaries on the other. Structure and delivery 


\begin{abstract}
Name: Lingulstic Landscape assignment
Descripticn. Rather than a descriptive account of your designated street, or worse, merely quantifylng typos or languages, the goal is to reach deeper and (i) contextualize your data (4 minutes): briefly introduce your designated street and then justify your data collection procedures. Where did you go? What did you make pictures of? Why? What did you expect to find? How did you orpanize and code your dataset? (ii) qualify your data (8 minutes): present an empirically and theoretically grounded interpretation of your fieldwork. Obviously, you will not be able to present 25 pictures, so make sure your selected pictures (no fewer than 5 , no more than 8 ) illustrate the analytical point(s) you're tying to make. Both criteria will be used to assess your work, along with delivery and QSA handling.
\end{abstract}

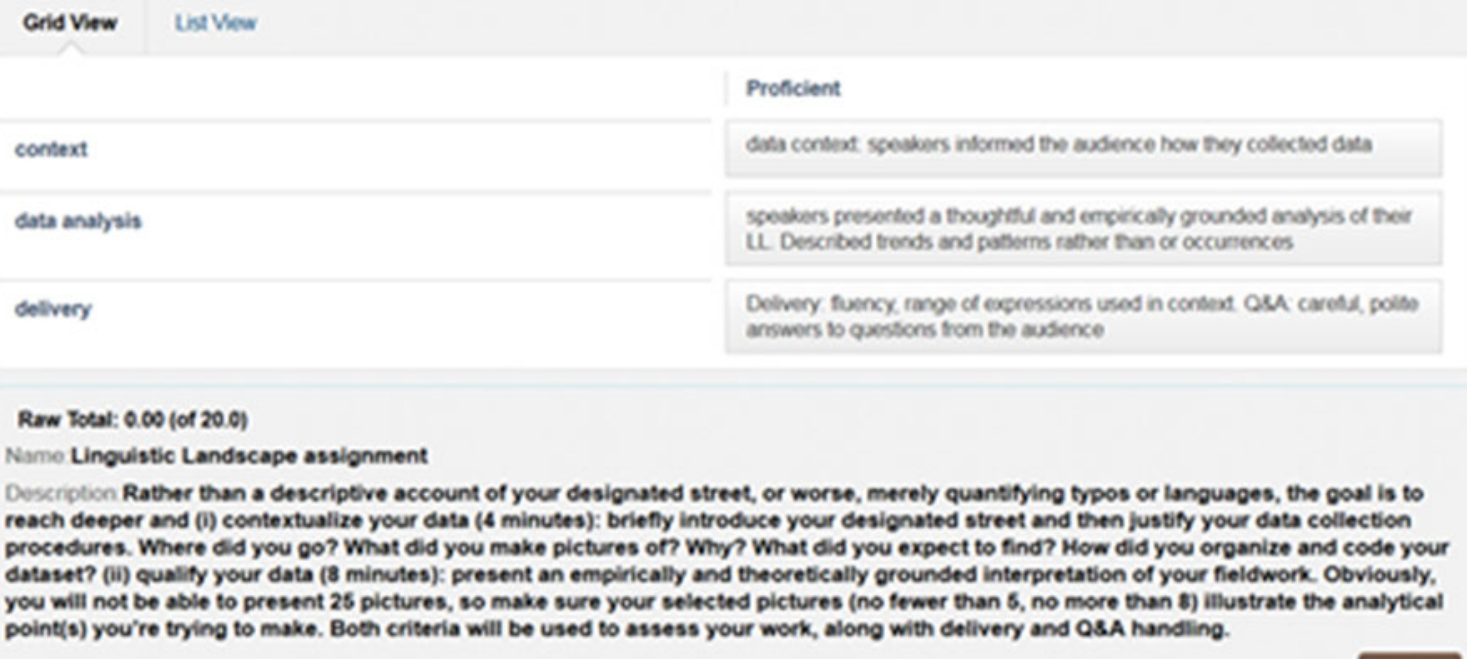

Fig. 3. Grading rubric Linguistic Landscape assignment.

were decent to outstanding. While the courses we teach are not methodology courses, we did insist on analytical transparency and required that students (1) inform the audience how they collected their data; (2) present a thoughtful and empirically grounded analysis of their survey area and describe trends and patterns rather than occurrences, informed by relevant research literature. In addition, we evaluated their (3) delivery and handling of questions from the audience. We designed a grading rubric, explicitly listing our performance expectations for the assignment. (See Fig. 3.)

Overall, we were happy to see that even without formal training in LL fieldwork, and without repeated visits to the field, students were able to conduct a "rapid" linguistic ethnography of entrepreneurial communication. We attribute this success to the appropriately narrow empirical focus (one street/one square), the team effort and commitment, and the peer pressure involved-the majority of the research teams conducted their fieldwork on the same day.
The main takeaway of the assignment is that $\quad 527$ students became aware of "the degree of linguistic 528 innovation, semiotic creativity, or ethnocultural 529 stereotyping that can be expected in certain 530 business sectors" [13]. While they initially struggled 531 to see the link with professional communication 532 (see How this Case Was Studied, above), changing 533 the focus to entrepreneurial communication proved 534 productive, promoting a rhetorical understanding $\quad 535$ of entrepreneurship communication outside the $\quad 536$ narrow confines of the organization and outside of 537 the comfort zone of the lecture room. For instance, $\quad 538$ students reported that (1) on the high street, 539 English serves as a cost-effective marketing code $\quad 540$ (i.e., one campaign/slogan/ad to be used in 541 different countries); (2) in multilingual countries 542 such as Belgium, English serves as a neutral (i.e., 543 sociolinguistically unmarked) lingua franca; and (3) 544 English is often used for its creative potential in 545 bilingual word play ("Flemish stew is good for you"). 546

After their presentations, student research teams were given a grade, and in addition to the grading rubric, we supplied a written evaluation. Here are 
two examples of written evaluation (the first was for a strong effort, the second was for an average one):

(1) All boxes ticked. Empirically grounded and theoretically informed, coherent and easy to follow presentation, delivered with flair and proficiency (jargon used in context, presentation was informed by relevant research, delivery was fluent and accurate). The audience was able to see how you arrived at your findings \& conclusions (e.g., the tension between local and global discourse practices, with a hint of "Flamisch"). Honest, fair responses during the Q\&A sequence. A mature effort. Congratulations.

(2) Well prepared and easy-to-follow presentation, despite the bullet-point-heavy slides. Telling the audience that you "found some interesting articles" is one thing; showing how the literature informed your analysis is quite another (disclose your sources!). Clever move to talk about five functions, even though I wasn't able to tell them apart. How, for instance, does one distinguish between signs invoking "international allure" (function number 4) and brand communication (function number 3)? Your observations were visually illustrated and you made an effort to contextualize and narrate your findings. Delivery: some minor issues ("English is used monolingual ${ }^{* *} 1 y^{* *}$ "), but none that interfered with comprehension.

\section{Conclusions, Limitations, and Suggestions FOR FURTHER RESEARCH}

This teaching case picks up on a long-running but nonetheless current debate on the challenges of globalization for professional communication programs. "Because globalization involves increasing interactivity and integration-processes that involve the blurring, shifting, and crossing of boundaries as well as the hybridizing and pluralizing of individual identities and societies-professional communicators must increasingly be able to navigate, negotiate, and cross these boundaries" [16]. Our aim in developing a LL assignment for master's students of professional communication was to teach them to navigate these hurdles. We challenged them to examine the "communication-related challenges, abilities and barriers" [14] from the perspectives of entrepreneurs writing for a globalized marketplace.

We pointed students at the value of lookalike language as a linguistic resource: rather than dismiss it as bad or deeply non-native English, lookalike English communicates socially relevant information about entrepreneurs and service providers in globalized cities around the world. In this way, we wanted to show them that the new breed of entrepreneur must think and speak globally, discover and conceptualize problems, and then solve those problems with innovative solutions [17]. While entrepreneurs must be able to identify opportunities, gather resources, and strike deals, they must also possess soft skills, like "social perception (the ability to perceive others accurately), expressiveness (the ability to express feelings and reactions clearly and openly), impression management (skill in making favorable first impressions on others), and social adaptability (proficiency in adapting one's actions to current social contexts)" [21].

Post-hoc interviews with students demonstrate that documenting and sharing lived experiences with peers and instructors encourages self-monitoring, and inspires them to view existing knowledge/practices in different contexts and give different meanings to that knowledge or those practices. As a pedagogical tool, then, the LL is an underused methodology rife with possibilities for exploring entrepreneurial communication in all of its breadth and variety, providing access to perhaps the most visible and creative materialities of entrepreneurs and service providers: shop windows and signs.

Suggestions for Further Research As Dewey reminded us, "We never educate directly, but indirectly by means of the environment" [22]. Disrupting the familiarity of a lecture room challenges students to consider alternative perspectives and reflect on attitudes previously thought of as common sense. It makes evident things into puzzles, and provokes fresh perceptions and a more reflective approach to the taken-for-granted. Immersion in the field presents the language skills to be acquired not as lessons to be learned but rather as something to be taken up into their own experience, in order to maintain an intimate connection between knowing and doing.

To stretch experiential learning even further, follow-up research could investigate the effects of enabling business practitioners to actively engage with and participate in the in-class discussions. Another avenue of research worth exploring is the potential of using LL research for listing key themes professional communication teachers and program developers might attend to as they design or revise courses and programs. A final suggestion 
would be to extend the scope of the assignment to include not only perceived spaces, but also conceived spaces: using newspaper articles, websites covering nearby events, and local census data, as well as maps and other documents, would tension between convention and creativity in entrepreneurial communication.

Limitations Needless to say, the students' learning experience was inherently ill structured. The outcomes varied based on the social setting and the scene. Learning in this way requires an approach that is highly constructivist and typically team-based or social. In this process of experiential learning, the lecturer is not so much a teacher but a coach, facilitating the negotiation of meaning and reflection about the learning process. On top of that, teachers need to be good at answering students' questions on the spot, even when their undoubtedly increase students' awareness of the misconceptions are unclear because they are still processing the information. however, is the evidence listed in the post-hoc business students develop a key quality of high-achieving professional communicators: "Adaptive to complexity in the workplace; can interpret what they need to know on the fly" [23]. If students are to become successful in the modern corporate world, they must gain many diverse experiences that they can use to transform and adapt themselves to fast-changing circumstances throughout their lives. Being global may not be a pursuit for the fainthearted, but a linguistic landscaping exposure to real life, careful coaching along the way, and in-class discussion about these messy fieldwork experiences may help attain that goal.
Counterbalancing this limitation (or challenge), interviews which shows that the assignment helped

\section{REFERENCES}

[1] E.-M. Jakobs and C. Spinuzzi, "Professional domains: Writing as creation of economic value," in Handbook of Writing and Text Production, E.-M. Jakobs and D. Perrin, Eds. Berlin: De Gruyter, 2014, pp. 359-384.

[2] E. Fischer and R. A. Reuber, "Online entrepreneurial communication: Mitigating uncertainty and increasing differentiation via Twitter," J. Bus. Venturing, vol. 29, no. 4, pp. 565-583, 2014.

[3] L. Brender, "Writing at Riverside Health Services: An ethnographic study in entrepreneurial communication," Bus. Prof. Commun. Quart., vol. 68, no. 3, pp. 335-339, 2005.

[4] A. Peck and F. Banda, "Observatory's linguistic landscape: Semiotic appropriation and the reinvention of space," Social Semiotics, vol. 24, no. 3, pp. 302-323, 2014.

[5] J. A. Schumpter, The Theory of Economic Development: An Inquiry into Profits, Capital, Credit, Interest, and the Business Cycle, vol. 55, New Brunswick, NJ, USA: Transaction Publishers, 1934.

[6] A. Appadurai, "Disjuncture and difference in the global cultural economy," Theory, Cult. Soc., vol. 7, no. (2), pp. 295-310, 1990.

[7] E. Reimer, E.-M. Jakobs, A. Borg and B. Trevisan, "New ways to develop professional communication concepts," in Proc. IEEE Prof. Commun. Conf., 2015, pp. 97-103.

[8] C. Spinuzzi, E.-M. Jakobs and G. Pogue, "A Good idea Is not enough: Understanding the challenges of entrepreneurship communication," in Proc. Int. Conf. Compet. Eng.-Resource Efficiency for Global Competitiveness, 2016, pp. 547-552.

[9] J. Swarts and L. Kim, "Guest editors' introduction: New technological spaces," Tech. Commun. Quart., vol. 18, no. 3, pp. 211-223, 2009.

[10] B. Rampton, J. Maybin and C. Roberts, "Theory and method in linguistic ethnography," in Linguistic Ethnography: Interdisciplinary Explorations, J. Snell, S. Shaw and F. Copland, Eds. Houndsmills, Basingstoke: Palgrave Macmillan, 2015, pp. 14-50.

[11] J. Blommaert, "Lookalike language," English Today, vol. 28, no. 2, pp. 62-64, 2012.

[12] C. Chern and K. Dooley, "Learning English by walking down the street," ELT J., vol. 68, no. 2, pp. 113-123, 2014.

[13] J. Androutsopoulos, "Computer-mediated communication and linguistic landscapes," in Research Methods in Sociolinguistics: A Practical Guide, J. Holmes and K. Hazen, Eds. Hoboken, NJ, USA: Wiley, 2014, pp. 74-90.

[14] D. Malinowski, "Opening spaces of learning in the linguistic landscape," Linguist. Landscape, vol. 1, no. 1-2, pp. 95-113, 2015.

[15] P. Sayer, "Using the linguistic landscape as a pedagogical resource," ELT J., vol. 64, no. 2, pp. 143-154, 2010.

[16] L. Rowland, "The pedagogical benefits of a linguistic landscape project in Japan," Int. J. Bilingual Educ. Bilingualism, vol. 16, no. 4, pp. 494-505, 2013.

[17] D. Dagenais, D. Moore, C. Sabatier, P. Lamarre, and F. Armand, "Linguistic landscape and language awareness," in Linguistic Landscape: Expanding the Scenery, E. Shohamy and D. Gorter, Eds. London, UK: Routledge, 2009, pp. 253-269.

[18] J. Dewey, The School and Society. Chicago, IL, USA: University of Chicago Press, 1907.

[19] J. Blommaert, "Sociolinguistics," in The Routledge Companion to English Studies, C. Leung and B. V. Street, Eds. London, UK: Routledge, 2014, pp. 131-145.

[20] K. Tracy and J. C. Mirivel, "Discourse analysis: The practice and practical value of taping, transcribing, and analyzing talk," in Handbook of Applied Communication, L. Frey and K. Cissna, Eds. Mahwah, NJ, USA: Erlbaum, 2009, pp. 153-177. 
[21] R. A. Baron and J. Tang, "Entrepreneurs' social skills and new venture performance: Mediating mechanisms and cultural generality," J. Manage., vol. 35, no. 2, pp. 282-306, 2009.

[22] J. Dewey, Democracy and Education: An Introduction to the Philosophy of Education. New York, USA: Macmillan, 1961.

[23] K. Schriver, "What we know about expertise in professional communication," in Past, Present, and Future Contributions of Cognitive Writing Research to Cognitive Psychology, V. W. Berninger, Ed. New York, USA: Psychology Press, 2012, pp. 275-312.

Tom Van Hout is Assistant Professor and Academic Director of the Institute for Professional and Academic Communication at the University of Antwerp, Belgium. He is also with the

Department of Journalism and New Media at Leiden University, the Netherlands.
Ellen Van Praet is Assistant Professor and Coordinator of the Research Centre for Multilingual Practices and Language Learning in Society (MULTIPLES) at Ghent University, Ghent, Belgium. 
Q1. Author: Please provide the city and postal code.

Q2. Author: Please provide the postal code.

Q3. Author: Please provide the city of universities. 
1 Teaching Case

2 Lookalike Professional English

\title{
- Tom Van Hout and Ellen Van Praet
}

\begin{abstract}
Background: Our teaching case reports on a fieldwork assignment designed to have master of arts students experience first-hand how entrepreneurs write for the globalized marketplace by examining public displays of language, such as billboards, shop windows, and posters. Research questions: How do entrepreneurs use English to "style" themselves? What is the status of English in public displays? Which relationship with customers is cultivated by using English (among other languages)? How does English, or lookalike versions thereof, create a more innovative business? Situating the case: We use linguistic landscaping as a pedagogical resource, drawing on similar cases in a local English as a foreign language (EFL) community in Oaxaca, Mexico; EFL programs in Chiba-shi, Japan; francophone and immersion French programs in Montreal, QC, Canada and Vancouver, BC, Canada; and a study of the entrepreneurial landscape in Observatory's business corridor of Lower Main Road in Cape Town, South Africa. How this case was studied: We interviewed 36 students about their learning process in one-to-one post hoc interviews. Recurrent themes were increased self-monitoring, improved professional communication literacy, and expanded real-world understanding. About the case: The teaching case follows a three-pronged approach. First, we have students decide on a survey area, determine their empirical focus, establish analytical units, decide how to collect data, collect (sociodemographic) information about their survey area, and determine the degree of researcher engagement. Next, students conduct fieldwork, documenting the linguistic landscape in small teams of three to four students. In the third phase, students have returned from the field and discuss their initial findings, ideas, and observations during a data session with the instructors. Students decide whether they still stand by the decisions they made before they entered the field and are then asked to qualify how language is used in public space. Results: The main takeaway of the assignment is that students were more aware of the degree of linguistic innovation, rhetorical creativity, and ethnocultural stereotyping of entrepreneurial communication in their cities. Conclusion: As a pedagogical tool, LL offers possibilities for exploring entrepreneurial communication in all of its breadth and variety, providing access to perhaps the most visible and creative materialities of entrepreneurs and service providers: shop windows and signs.
\end{abstract}

Index Terms-Entrepreneurship communication, linguistic landscape, lookalike English, professional communication.

Managing a business inevitably involves the rhetorical activity of creating value through writing [1], both online [2] and offline [3]. This teaching cases addresses the creation of economic value from the perspective of writing for the globalized marketplace. We send students on a semiotic safari in urban environments, where they encounter professional communication in multilingual couleur locale. We have them document the bits of English used by professional communicators on billboards, in shop windows, posters, graffiti, and other inscriptions. The rationale is that such displays of entrepreneurial communication offer a convenient

Manuscript received February 15, 2016; revised May 30, 2016; accepted July 5, 2016. Date of publication; date of current version.

T. Van Hout is with the Institute for Professional and Academic Communication at the University of Antwerp, Belgium, and the Department of Journalism and New Media, Leiden University, the Netherlands (email: tom.vanhout@uantwerp.be).

E. Van Praet is with the Research Centre for Multilingual Practices and Language Learning in Society, Ghent University, Ghent, Belgium (email: Ellen.VanPraet@UGent.be).

Color versions of one or more of the figures in this paper are available online at http://ieeexplore.ieee.org. and socioculturally rich space for studying rhetorical action in situ [4].

\section{Overview of the Case}

nnovation and entrepreneurship are studied in many disciplines, including economics, sociology, psychology, linguistics, and anthropology. In the traditional Schumpeterian view, the innovation-management process is considered linear and continuous. In this teaching case, however, we adopt an approach to entrepreneurship that complements Schumpeterian innovation dynamics [5] with Appadurian scalar dynamics [6], and recognize that change in a globalized market is, by definition, chaotic, nonlinear, and unpredictable.

In his work on the cultural dimensions of globalization, anthropologist Arjun Appadurai famously argued that the global economy needs to be "understood as a complex, overlapping, disjunctive order" [6], composed of cultural flows between people, media, technologies, capital, and ideologies. Disturbing the even flow of production and creating new ways of doing, the Schumpeterian 
entrepreneur will instigate innovative language practices and, hence, unforeseen, artful, or otherwise "new combinations" of entrepreneurial communication. In other words, disjuncture also triggers rhetorical innovation.

Following this rationale, our teaching case addresses the following research questions:

RQ1. What are the effects of globalization on entrepreneurial communication?

RQ2. How do entrepreneurs use English to "style" themselves?

RQ3. Which relationship with customers is cultivated by using English (among other languages)?

RQ4. How does English, or lookalike versions thereof, create more innovative business signage?

In what follows, we report on how we coached and monitored students as they collected data in the field to answer these research questions. We explain the underlying rationale for developing the assignment and discuss implications for teachers and students of professional communication.

In line with other researchers of professional communication in Europe [7], [8], we draw on linguistics to understand how rhetorical action is accomplished. Specifically, we focus on public signage as a technological space for rhetorical action [9]. Rather than the outcome of a formal research project, this teaching case results from (1) our experience as instructors of professional communication, and (2) our backgrounds in sociolinguistics and linguistic ethnography. An umbrella term for ethnographic approaches to language and communication. Linguistic ethnography holds that "the contexts of communication should be investigated rather than assumed [and that] analysis of the internal organisation of verbal (and other kinds of semiotic) data is essential to understanding its significance and position in the world" [10].

In what follows, Situating the Case outlines the key studies and theories that guided the design of the assignment. How the Case was Studied explains why we relied on experiential learning as a pedagogical approach and why the assignment took on a clearer focus on entrepreneurial communication over time. About the Teaching Case describes how students were briefed, how they performed during data sessions with the instructors, and how they analyzed their data.
Conclusions, Limitations, and Suggestions for

Future Research spells out implications for teaching practice, the limitations of this case, and avenues for future research.

\section{Situating the Case}

This section identifies the literature that informed the teaching case. We start with the three source texts that inspired and provided the main scaffold for the case in How Literature Was Selected, followed by a discussion of similar cases.

How Literature Was Selected Our teaching case draws on recent debates in two fields: sociolinguistics and foreign language pedagogy. First and foremost, we were triggered by the concept of lookalike language [11]. Proliferating in urban spaces around the world, the bits of English used by professional communicators on billboards, in shop windows, posters, graffiti, and other inscriptions often appear "in forms and formats that challenge our understanding of language" [11]. They come with accents, typos, dialects, unintended meanings. They "sufficiently look like English, even if the English they display makes no sense at all linguistically. Their function is not to express coherent linguistic meanings through the system of English. It is, rather, to show and display an awareness of the potential social capital contained in forms and shapes connected to English" [11].

Rather than simply dismiss lookalike language as bad or non-native English, the concept compelled us to study occurrences of lookalike English as indicators of social change. (See also [12].) If students are to become successful in the modern globalized corporate world, they have to come to terms with the diversity, and "the unpredictability, which comes along with highly mobile, technological and multicultural citizens" [4]. Since no classroom experience can provide such knowledge first-hand, we turned to the sights and sounds of the city.

We used a linguistic landscape (LL) approach, a young and vibrant area of sociolinguistics that studies how written language constructs public places. LL research examines billboards, road signs, shop windows, graffiti, and other inscriptions in urban environments. Our second source of inspiration was an LL research assignment, developed by sociolinguist Jannis Androutsopoulos 
(1) Selection of a site

(2) Photographic documentation

(3) Selection of and contact with participants

(4) Conducting individual "walking tour" interviews on the selected site

(5) Transcription and analysis of interviews and field notes

(6) Reflection

Skipping Androutsopoulos' stages 3, 4, and 5, we structured our assignment around three phases. First, we let students decide on a survey area, determine their empirical focus, establish analytical units, decide how to collect data, collect (sociodemographic) information about their survey area, and determine the degree of researcher engagement. In the second phase, they conduct fieldwork, taking pictures, and documenting the linguistic landscape in small teams. In the third, reflective phase, students have returned from the field and discuss their initial findings, ideas, and observations during a data session with the instructor. Students decide whether they still stand by the decisions that they had made before they entered the field and are asked to qualify how language is used in public space. In this phase, students interpret the social actions accomplished by the signs and present their findings to their peers in a student research conference.

A third source of inspiration was found in Malinowski's [14] creative adoption of Henri Lefebvre's triple notion of conceived, perceived, and lived spaces for language learning. Applying the triadic model to second language pedagogy, Malinowski argues for a study of at least two dimensions in the LL. In terms of language learning, then, this approach means that students do not just visit areas with signs in the target language (English); or take pictures and sample lookalike language (perceived spaces); or conduct interviews with local entrepreneurs to probe for experiences, memories, and feelings (lived spaces). Ideally, students do all of these, alongside textual analysis of language policy documents, newspaper articles, and other media representations (conceived spaces).

Similar Cases In designing the teaching case, we were guided by a recent interest in using the LL as a pedagogical resource in second and foreign language learning in Mexico [15], Japan [16], and Canada [17]. Along the way, we discovered that using the LL as a site for business English learning seemed in largely unexplored territory. We were also inspired by Peck and Banda, who point an ethnographic lens at the entrepreneurial landscape in Observatory's business corridor of Lower Main Road in Cape Town, South Africa [4]. Their paper explores the development of an "African Corner" within Lower Main Road, and documents sociocultural change in ways that a population census could never uncover. In particular, their analysis shows how some Asian and African entrepreneurs openly celebrate Africanness and use it as an innovative marketing strategy, while others shy away from the overt use of signage, art, and texts that might foreground their Africanness.

\section{How This Case Was Studied}

In what follows we explain why we opted for autonomous, experiential learning as a pedagogical approach and why the assignment took on a clearer focus on entrepreneurial communication.

Advocating experiential learning in education is by no means new. Back in the early $19^{\text {th }}$ century, John Dewey argued for incorporating as much of current society into the educational process as possible to facilitate learning, which would then enhance society as a whole [18]. More recent studies show that experiential learning in business and accounting programs has become increasingly important. It has now become a taken-for-granted assumption among business and management educators and CEOs that universities must provide experiential learning programs, such as internships, real-life marketing cases, crisis communication, advertising, and the like. Business education-like the firms and students they serve-is in a continuous process of evolving to meet a shifting global and local environment. Fast-changing corporate settings, along with students' ever-increasing access to mobile technology and mediated content, force business programs to rethink how student learning can be facilitated to make class time and activities as relevant and valuable as possible.

Following this rationale, Author 1 piloted the assignment in 2014 at the University of Antwerp, where he teaches professional communication in English to about 70 students in the Master of Multilingual Professional Communication program. One year later, a slightly altered version of the assignment was launched by Author 2 at Ghent University for about 60 students of the Master of Multilingual Communication program. Both master's programs train students in multilingual communication skills for business, government, and nonprofit organizations. The master's program

\section{(16)}

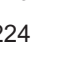

\section{.}


is typically—but not exclusively-populated by students with a background in (applied) linguistics. The courses in which the assignments were taught are required for all students registering for the two programs. Sessions with students were held on a once-a-week basis. A typical semester in Belgium starts at the end of September and lasts 12 weeks. At the University of Antwerp, six weeks were reserved for the assignment. At Ghent University, time for completing the assignment was limited to three weeks.

Since experiential learning is a complex construct and, therefore, difficult to measure, we tested our approach by interviewing 36 students about what they had learned in the course. In these one-to-one exit interviews, recurrent themes were increased self-monitoring, improved professional communication literacy, and expanded real-world understanding, but also a failure to see a link with professional communication in a foreign language. In fact, at the beginning, in Year 1, the assignment did not focus on entrepreneurial communication per se. Its scope was more general, focusing on aspects of language use in a globalized city. To better serve student needs, we adjusted the pilot version of the assignment in Year 2, addressing what students had identified as its strengths (lived experience) and shortcomings (lack of focus). This revised version of the assignment is the basis for the teaching case presented in this paper.

\section{About the Teaching Case}

This section describes the trigger for developing the case, the design of the assignment, the changes we made to each version of the assignment, and the results of our efforts, grounded in reflections and feedback from students.

Problem The LL assignment addresses three broad but related issues we encountered as instructors of professional communication in a foreign language.

(1) Managing student expectations: Students entered the course with the expectation that they would learn about professional communication from the perspective of native speakers in monolingually English corporate environments. But real-world communication-what with its creative language practices, and oddly peculiar local meanings - tends to have a disruptive effect on such ideals. In fact, we wanted students to engage with English as sociolinguists would: as an instrument of mobility, dislodged from resident, stable communities of speakers and freely moving across the globe in unpredictable flows [19].

(2) Engaging with multilingual resources: A learner's trajectory in English as a second or foreign language is commonly described in terms of acquiring monolingual fluency in the target language. For instance, the Common European Framework of Reference for Languages plots language proficiency on a scale from "basic user" over "independent user" to "proficient user." Such scales not only skate over the range of language resources that people use to make meaning (speech styles, jargon, genres, register) but also neglect the smatterings of other languages that speakers rely on to get meaning across. Observing and documenting LLs draws students' attention to the "multilayered, and often bitterly contentious processes by which sign-mediated, social meanings are produced in place" [14].

(3) Banking on lived experience: Whereas in more traditional ways of teaching professional communication skills, first exposure occurs via lectures, role plays, or simulations in class, we wanted students to examine first-hand contexts of entrepreneurial communication. Observing business communication in urban environments and interpreting it in the company of peers and instructors afterwards makes professional communication training in a foreign language not only more authentic, meaningful, and motivating but also produces richer in-class discussions of the social meanings of entrepreneurship communication, ultimately leading to a level of metacognition and reflection associated with deep learning.

Students were given three to six weeks to read up on LL research, conduct fieldwork, interpret their data, and present their findings in class. In addition to this time constraint, academic heterogeneity was a complicating factor. Both master's programs bring together students with backgrounds in (primarily) applied linguistics, communication, and applied economics. While we see this diversity as a strength rather than a weakness, it does require an effort to find common ground to describe and interpret the social meanings of entrepreneurial communication. Inevitably, some students will be familiar with the technical vocabularies of linguistics, while others will need to make an extra effort. To cope with the heterogeneity, and address students' diverse competency levels in sociolinguistics, we made sure 


\begin{tabular}{|c|c|}
\hline empirical focus & $\begin{array}{l}\text { linguistic innovation, semiotic creativity, ethnocultural } \\
\text { stereotyping, usage and status of English, unexpected } \\
\text { language combinations, lookalike language use, target } \\
\text { audience, social status }\end{array}$ \\
\hline analytical unit & $\begin{array}{l}\text { individual sign, shop window, specific chunk of space, which } \\
\text { material aspects, moving or static signs, mobile signs }\end{array}$ \\
\hline data collection & camera, smartphone, time of day, storage \\
\hline research area & $\begin{array}{l}\text { demographic or census data, location (Google Maps), } \\
\text { historical development, urban development plans and the like }\end{array}$ \\
\hline $\begin{array}{l}\text { degree of researcher } \\
\text { engagement }\end{array}$ & $\begin{array}{l}\text { snapshot observation and documentation (no engagement } \\
\text { with "the locals") or interacting with research sites and } \\
\text { participants; decisions about when, how and who to interview }\end{array}$ \\
\hline
\end{tabular}

Fig. 1. Pre-fieldwork decisions.

that they were equipped with reading materials and background knowledge of the methodology used. In Antwerp, students were instructed to read and discuss an academic article about LL research during class. In Ghent, a guest lecture on LL provided a point of departure, along with a classroom discussion on an LL research paper they were instructed to read.

Solution The purpose of the linguistic landscape assignment was to have master's students examine first-hand how entrepreneurs, such as business owners and service providers, make use of commercial space in urban environments by studying public displays of language in marketplace examples, such as billboards, shop windows, and posters. We circulated sign-up sheets with selected survey areas in Antwerp and Ghent. Students signed up in teams of 3 to 4 . To narrow their empirical focus, they answered the following questions:

(1) How are you going to organise your research team? Who is responsible for what?

(2) What data are you going to collect and why? Photos? Audio? Video? Field notes?

(3) What is the unit of analysis?

(4) What are the potential pitfalls of

(a) Carrying out fieldwork?

(b) Analysing the resulting data?
(5) How will you categorise your data?

(6) When choosing the data for presentation, what do you need to take into account?

(7) What additional information do you have/do you need about your street/square? Where can you find it?

In designing these questions, we relied on Androutsopoulos' listing of pre-fieldwork decisions [13]. (See Fig. 1.)

After thinking about and talking through the prefieldwork questions, students spread out all over the city to map the linguistic repertoire (which language[s]? what linguistic "bits"?) and language ranking (a top 10 of languages encountered) for their designated square or street. They collected photographs (see the example in Fig. 2), and live tweeted the research process using the designated course hashtags \#LLMPC15 and \#A4MC1516. While they were out in the field, we relied on the Twitter livestream to interact with them.

Process for Developing the Solution Having returned from the field with a bag full of observations, notes, and photographs, students were given feedback on how to analyze their data and make sense of their-at first glance-banal impressions. They were given the opportunity to discuss their preliminary findings during a data 


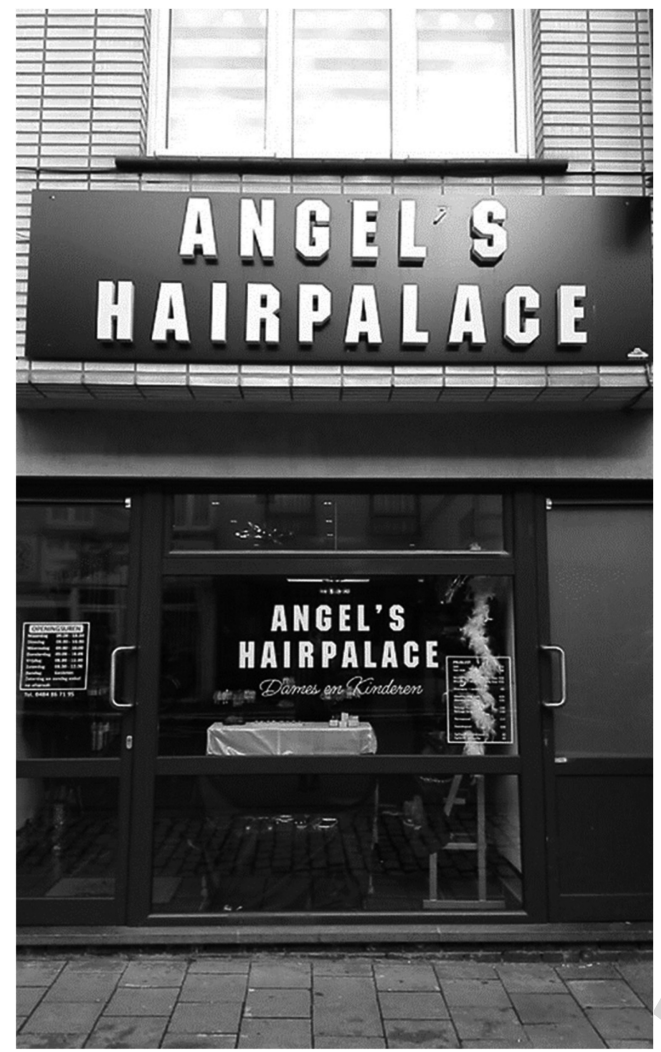

Fig. 2. Lookalike English: Angel's Hairpalace.

session. These sessions were run as peer-reviewed research consultations: two teams per 25-minute slot, 12 minutes per team. The goal of a data session was to try out "arguments on equally observant others ... and construct more insightful and persuasive analyses" [20].

During the sessions, we gave students advice on how to turn their dataset into an organized dataset from which they could draw significant trends or representative qualities. More specifically, we challenged students to look for clues about how entrepreneurial language is used and offered reading tips. In other words, we challenged them to determine relevant context (a crucial skill for budding professional communicators). Here is an excerpt from the data session briefing:

You will have observed a variety of business Englishes: carefully designed, expensive signs in perfect English as well as odd, elastic varieties of English so to speak. Some will have an "accent" ("love prices" instead of "lovely prices"). Now, you can dismiss those varieties as ungrammatical or substandard out of hand, but it gets far more interesting if you dig deeper.
Digging deeper means trying to determine which aspects of context are made relevant. The given context is what the sign communicates directly ("denotes"). Literal meanings. Product $x$ or $y$ is on sale. Categorize those meanings into functions. What is this sign doing here? Informing, persuading, promoting, you name it.

Signs (or "semiotic resources"-the tools we have at our disposal to make meaning) can also suggest or point to more subtle, indirect meanings. Signs often presuppose ("index") relevant context. For instance, English or French words in store names to signal prestige.

If you try to interpret how and why English is used, you'll find that public space is regimented (or governed by expectations of normative conduct): in order to attract rich clients, high end clothing shops will style themselves in particular ways. You will not for instance, expect to find hand-written signs in a Chanel store. You will however find such signs in a night shop.

There are no hard and fast rules for determining relevant context. What you can do is go over your data thoroughly and repeatedly and formulate ideas and interpretations of how you think English is being used in the marketplace.

One takeaway from the data sessions was that students found the fieldwork exciting but hard. Many students struggled to make sense of the unexpected linguistic practices they had observed, while others felt that their fieldwork was a failure because they found little or no diversity in the more commercial areas of town. Students also inquired about our expectations for the final deliverable. We replied by repeating what was on the assignment sheet: "Present an empirically and theoretically grounded interpretation of your fieldwork. Justify your data collection, reduction, and analysis, and interpret your findings. Show pictures. Reflect on what you have learned about the use of English in the marketplace but avoid linear, descriptive accounts of your research ("Here we see this and there that"-cue Ralph Wiggum: "Boring!"). We like a good story as much as you do."

Results Conducting research is an exercise in transparency, so we requested that students share their presentations and disclose their raw data (pictures) using a file-sharing service. The student presentations were a mixed bag of theoretically informed and empirically grounded accounts on the one hand, and overly descriptive and arid summaries on the other. Structure and delivery 


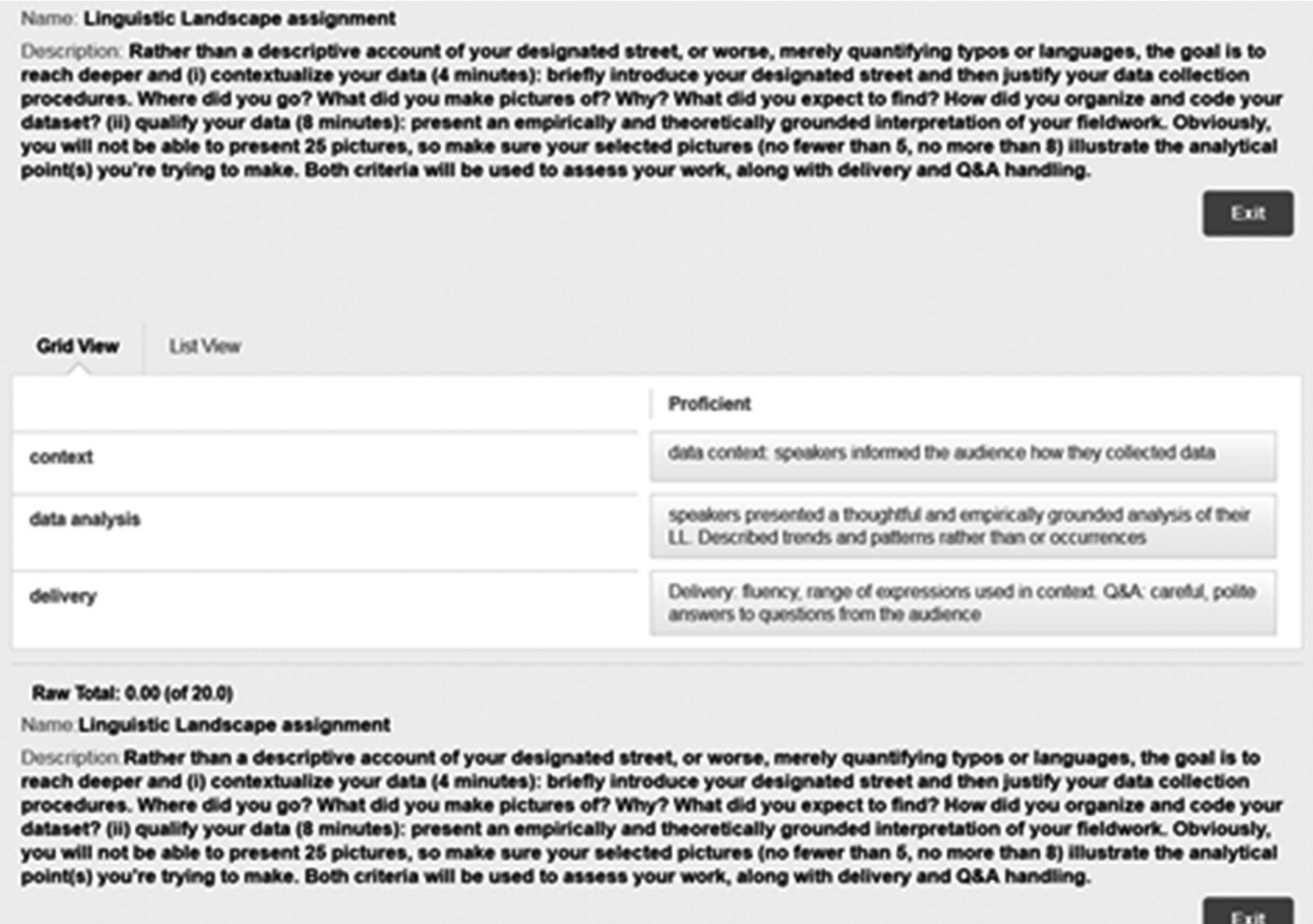

Fig. 3. Grading rubric Linguistic Landscape assignment.

were decent to outstanding. While the courses we teach are not methodology courses, we did insist on analytical transparency and required that students (1) inform the audience how they collected their data; (2) present a thoughtful and empirically grounded analysis of their survey area and describe trends and patterns rather than occurrences, informed by relevant research literature. In addition, we evaluated their (3) delivery and handling of questions from the audience. We designed a grading rubric, explicitly listing our performance expectations for the assignment. (See Fig. 3.)

Overall, we were happy to see that even without formal training in LL fieldwork, and without repeated visits to the field, students were able to conduct a "rapid" linguistic ethnography of entrepreneurial communication. We attribute this success to the appropriately narrow empirical focus (one street/one square), the team effort and commitment, and the peer pressure involved-the majority of the research teams conducted their fieldwork on the same day.
The main takeaway of the assignment is that students became aware of "the degree of linguistic innovation, semiotic creativity, or ethnocultural stereotyping that can be expected in certain business sectors" [13]. While they initially struggled to see the link with professional communication (see How this Case Was Studied, above), changing the focus to entrepreneurial communication proved productive, promoting a rhetorical understanding of entrepreneurship communication outside the narrow confines of the organization and outside of the comfort zone of the lecture room. For instance, students reported that (1) on the high street, English serves as a cost-effective marketing code (i.e., one campaign/slogan/ad to be used in different countries); (2) in multilingual countries such as Belgium, English serves as a neutral (i.e., $\quad 543$ sociolinguistically unmarked) lingua franca; and (3) 544 English is often used for its creative potential in 545 bilingual word play ("Flemish stew is good for you"). 546

After their presentations, student research teams were given a grade, and in addition to the grading rubric, we supplied a written evaluation. Here are 
two examples of written evaluation (the first was for a strong effort, the second was for an average one):

(1) All boxes ticked. Empirically grounded and theoretically informed, coherent and easy to follow presentation, delivered with flair and proficiency (jargon used in context, presentation was informed by relevant research, delivery was fluent and accurate). The audience was able to see how you arrived at your findings \& conclusions (e.g., the tension between local and global discourse practices, with a hint of "Flamisch"). Honest, fair responses during the Q\&A sequence. A mature effort. Congratulations.

(2) Well prepared and easy-to-follow presentation, despite the bullet-point-heavy slides. Telling the audience that you "found some interesting articles" is one thing; showing how the literature informed your analysis is quite another (disclose your sources!). Clever move to talk about five functions, even though I wasn't able to tell them apart. How, for instance, does one distinguish between signs invoking "international allure" (function number 4) and brand communication (function number 3)? Your observations were visually illustrated and you made an effort to contextualize and narrate your findings. Delivery: some minor issues ("English is used monolingual ${ }^{* *} 1 y^{* *}$ "), but none that interfered with comprehension.

\section{Conclusions, Limitations, and Suggestions FOR FURTHER RESEARCH}

This teaching case picks up on a long-running but nonetheless current debate on the challenges of globalization for professional communication programs. "Because globalization involves increasing interactivity and integration-processes that involve the blurring, shifting, and crossing of boundaries as well as the hybridizing and pluralizing of individual identities and societies-professional communicators must increasingly be able to navigate, negotiate, and cross these boundaries" [16]. Our aim in developing a LL assignment for master's students of professional communication was to teach them to navigate these hurdles. We challenged them to examine the "communication-related challenges, abilities and barriers" [14] from the perspectives of entrepreneurs writing for a globalized marketplace.

We pointed students at the value of lookalike language as a linguistic resource: rather than dismiss it as bad or deeply non-native English, lookalike English communicates socially relevant information about entrepreneurs and service providers in globalized cities around the world. In this way, we wanted to show them that the new breed of entrepreneur must think and speak globally, discover and conceptualize problems, and then solve those problems with innovative solutions [17]. While entrepreneurs must be able to identify opportunities, gather resources, and strike deals, they must also possess soft skills, like "social perception (the ability to perceive others accurately), expressiveness (the ability to express feelings and reactions clearly and openly), impression management (skill in making favorable first impressions on others), and social adaptability (proficiency in adapting one's actions to current social contexts)" [21].

Post-hoc interviews with students demonstrate that documenting and sharing lived experiences with peers and instructors encourages self-monitoring, and inspires them to view existing knowledge/practices in different contexts and give different meanings to that knowledge or those practices. As a pedagogical tool, then, the LL is an underused methodology rife with possibilities for exploring entrepreneurial communication in all of its breadth and variety, providing access to perhaps the most visible and creative materialities of entrepreneurs and service providers: shop windows and signs.

Suggestions for Further Research As Dewey reminded us, "We never educate directly, but indirectly by means of the environment" [22]. Disrupting the familiarity of a lecture room challenges students to consider alternative perspectives and reflect on attitudes previously thought of as common sense. It makes evident things into puzzles, and provokes fresh perceptions and a more reflective approach to the taken-for-granted. Immersion in the field presents the language skills to be acquired not as lessons to be learned but rather as something to be taken up into their own experience, in order to maintain an intimate connection between knowing and doing.

To stretch experiential learning even further, follow-up research could investigate the effects of enabling business practitioners to actively engage with and participate in the in-class discussions. Another avenue of research worth exploring is the potential of using LL research for listing key themes professional communication teachers and program developers might attend to as they design or revise courses and programs. A final suggestion 
would be to extend the scope of the assignment to include not only perceived spaces, but also conceived spaces: using newspaper articles, websites covering nearby events, and local census data, as well as maps and other documents, would undoubtedly increase students' awareness of the tension between convention and creativity in entrepreneurial communication.

Limitations Needless to say, the students' learning experience was inherently ill structured. The outcomes varied based on the social setting and the scene. Learning in this way requires an approach that is highly constructivist and typically team-based or social. In this process of experiential learning, the lecturer is not so much a teacher but a coach, facilitating the negotiation of meaning and reflection about the learning process. On top of that, teachers need to be good at answering students' questions on the spot, even when their misconceptions are unclear because they are still processing the information.

Counterbalancing this limitation (or challenge), however, is the evidence listed in the post-hoc interviews which shows that the assignment helped business students develop a key quality of high-achieving professional communicators: "Adaptive to complexity in the workplace; can interpret what they need to know on the fly" [23]. If students are to become successful in the modern corporate world, they must gain many diverse experiences that they can use to transform and adapt themselves to fast-changing circumstances throughout their lives. Being global may not be a pursuit for the fainthearted, but a linguistic landscaping exposure to real life, careful coaching along the way, and in-class discussion about these messy fieldwork experiences may help attain that goal.
[11] J. Blommaert, "Lookalike language," English Today, vol. 28, no. 2, pp. 62-64, 2012.

[12] C. Chern and K. Dooley, "Learning English by walking down the street," ELT J., vol. 68, no. 2, pp. 113-123, 2014.

[13] J. Androutsopoulos, "Computer-mediated communication and linguistic landscapes," in Research Methods in Sociolinguistics: A Practical Guide, J. Holmes and K. Hazen, Eds. Hoboken, NJ, USA: Wiley, 2014, pp. 74-90.

[14] D. Malinowski, "Opening spaces of learning in the linguistic landscape," Linguist. Landscape, vol. 1, no. 1-2, pp. 95-113, 2015.

[15] P. Sayer, "Using the linguistic landscape as a pedagogical resource," ELT J., vol. 64, no. 2, pp. 143-154, 2010.

[16] L. Rowland, "The pedagogical benefits of a linguistic landscape project in Japan," Int. J. Bilingual Educ. Bilingualism, vol. 16, no. 4, pp. 494-505, 2013.

[17] D. Dagenais, D. Moore, C. Sabatier, P. Lamarre, and F. Armand, "Linguistic landscape and language awareness," in Linguistic Landscape: Expanding the Scenery, E. Shohamy and D. Gorter, Eds. London, UK: Routledge, 2009, pp. 253-269.

[18] J. Dewey, The School and Society. Chicago, IL, USA: University of Chicago Press, 1907.

[19] J. Blommaert, "Sociolinguistics," in The Routledge Companion to English Studies, C. Leung and B. V. Street, Eds. London, UK: Routledge, 2014, pp. 131-145.

[20] K. Tracy and J. C. Mirivel, "Discourse analysis: The practice and practical value of taping, transcribing, and analyzing talk," in Handbook of Applied Communication, L. Frey and K. Cissna, Eds. Mahwah, NJ, USA: Erlbaum, 2009, pp. 153-177. 
[21] R. A. Baron and J. Tang, "Entrepreneurs' social skills and new venture performance: Mediating mechanisms and cultural generality," J. Manage., vol. 35, no. 2, pp. 282-306, 2009.

[22] J. Dewey, Democracy and Education: An Introduction to the Philosophy of Education. New York, USA: Macmillan, 1961.

[23] K. Schriver, "What we know about expertise in professional communication," in Past, Present, and Future Contributions of Cognitive Writing Research to Cognitive Psychology, V. W. Berninger, Ed. New York, USA: Psychology Press, 2012, pp. 275-312.

740 Tom Van Hout is Assistant Professor and Academic Director of 741 the Institute for Professional and Academic Communication at 742 the University of Antwerp, Belgium. He is also with the

743 Department of Journalism and New Media at Leiden University, 0374 the Netherlands.
Ellen Van Praet is Assistant Professor and Coordinator of the Research Centre for Multilingual Practices and Language Learning in Society (MULTIPLES) at Ghent University, Ghent, Belgium. 


\section{QUERIES}

Q1. Author: Please provide the city and postal code.

Q2. Author: Please provide the postal code.

Q3. Author: Please provide the city of universities. 